\title{
Thyme (Thymbra spicata L.), rosemary (Rosmarinus officinalis L.) and vitamin E supplementation of laying hens
}

\author{
T. Cimrin \\ Department of Animal Science, Faculty of Agricultural Science Hatay Mustafa Kemal University-31034, Hatay, Turkey
}

(Received 20 March 2019; Accepted 9 July 2019; First published online 18 November 2019)
Copyright resides with the authors in terms of the Creative Commons Attribution 4.0 South African License.
See: http://creativecommons.org/licenses/by/4.0/za
Condition of use: The user may copy, distribute, transmit and adapt the work, but must recognize the authors and the South African Journal of Animal Science.

\begin{abstract}
This study was conducted to determine the effects on performance, egg quality parameters and some serum profiles of vitamin E, thyme and rosemary extracts that were added to laying hen feeds. One hundred twelve 48-week-old Bovans-genotype white laying hens were used in the research. In the study, hens were randomly divided into four groups, each comprising of four replicates of seven hens. The first group was fed with the basal diet as a control. The other three groups were fed diets with $200 \mathrm{mg} / \mathrm{kg}$ vitamin E, with 1000 $\mathrm{mg} / \mathrm{kg}$ thyme, and with $1000 \mathrm{mg} / \mathrm{kg}$ rosemary for eight weeks. As a result, vitamin E increased egg production statistically compared with feeds with plant extracts. Thyme-supplemented feed increased egg weight significantly. However, it reduced egg production. Rosemary supplementation generated profit by reducing the feed intake, but had a negative effect by reducing egg weight and egg production. The cholesterol level in the blood serum decreased with thyme supplementation. In addition, blood triglyceride level decreased at a statistically significant level with the supplementation of both thyme and rosemary. In the light of these results, it can be said that the supplementation of vitamin E, thyme and rosemary extracts has a positive effect on some performance parameters and animal health. Since healthier products are obtained from healthy animals, the use of these natural additives in laying hen feeds could be recommended after dose trials.
\end{abstract}

Keywords: aspartate aminotransferase, cholesterol, egg production, feed intake, plant extract, triglyceride

"Corresponding author: tcimrin@hotmail.com

\section{Introduction}

Additives in animal feed are transferred to animal products and may pose a risk to human beings that consume these products. Therefore, demand for natural additives has increased compared with synthetic additives. However, these substances should primarily protect the animal's health, contribute to an increase in the product, and enhance its functionality naturally by improving its quality and shelf life in order to be used efficiently. Among many practices to meet these demands, vitamins and medicinal and aromatic plants have gained importance. In experimental studies conducted on the effects of aromatic plants, it was seen that thyme (Thymbra spicata L.) and its essential oil have anticandidal, antifungal, antioxidant and antimicrobial properties (Baser, 2008; Ünlü et al., 2009). In particular, carvacrol, one of the main compounds of the thyme plant, has mechanisms such as antimicrobial, antitumor, antimutagenic, antigenotoxic, analgesic, antispasmodic, antiinflammatory, angiogenic, antiparasitic, antiplatelet, antielastase, insecticidal, antihepatotoxic, and hepatoprotective activities (Baser, 2008). Thyme and the oil or extract that is obtained from it improve the digestion of nutrients by increasing the activity of digestion enzymes (Abd El-Wareth et al., 2012). Sage and thyme extracts improve some performance and quality parameters (Kaya \& Turgut, 2012). Moreover, extracts of plants such as thyme, rosemary and sage have a lowering effect on egg yolk (Kaya \& Turgut, 2012) and cholesterol and triglyceride levels in blood serum (Gerzilov et al., 2015). Similarly, herbal extracts (thyme and garlic) reduced the cholesterol of serum and yolk according to the control (Behnamifar et al., 2015). Dietary supplementation of carvacrol improves feed conversion efficiency and egg quality parameters (Beyazıtoglu, 2009). Additionally, the essential oils of $1000 \mu \mathrm{g} / \mathrm{ml}$ of rosemary and thyme were demonstrated to inhibit the contractions of the small intestine (Bulbul et al., 2018). Rosemary (Rosmarinus officinalis L.) has been reported as the plant having greatest antioxidative activity (Estevez et 
al., 2007; Wang et al 2008). In addition, rosemary has been reported to increase nutrient uptake and appetite, saliva secretion, the synthesis and digestion of bile acids and the absorption of lipids (Christaki et al., 2011). Since rosemary improves nutrient digestion, prevents microbial growth, and delays lipid oxidation, it is used as an alternative to synthetic antioxidants and antimicrobials in feeds (Hernandez et al., 2004; Çimrin \& Demirel, 2016b; Batista et al., 2017). It also improves production performance and antioxidant enzyme activity under temperature stress conditions (Torki et al., 2018), and has a positive effect on eggshell quality (Cufadar, 2018). Alagawany \& Abd El-Hack (2015) reported that production, performance and egg quality properties were improved with the supplement of $3000 \mathrm{mg} / \mathrm{kg}$ rosemary powder to laying hen diets. Belenli et al. (2015) determined that rosemary caused a decrease in cholesterol and partially on lipid concentration. Apaydin Yildirim et al. (2018) reported that certain biochemical parameters were improved with the supplementation of $200 \mathrm{mg} / \mathrm{kg}$ rosemary ethanol extract to chicken diets. An addition, vitamin E has been proved to be a powerful antioxidant. It strengthens the immune system and reduces the risk of disease. When added to the feed, it improves feed utilization and affects the egg production and liver functions (Iqbal et al., 2013; Çimrin \& Demirel 2016a). Wen et al. (2013) reported that dietary supplementation with $200 \mathrm{IU} / \mathrm{kg}$ vitamin $E$ improved egg production and egg quality, and played an important role in maintaining the growth of animals and improving the quality of livestock products, and blood parameters (Abdallah et al., 2017; Attia et al., 2018). Niu et al. (2018) reported that the efficacy of meat quality and antioxidant capacity in chickens fed with $200 \mathrm{mg} / \mathrm{kg}$ vitamin E diet was greater compared with those fed with $100 \mathrm{mg} / \mathrm{kg}$ vitamin E diet. Mu et al. (2019) reported that average daily feed intake, egg weight and egg production rose with increasing dietary vitamin E supplementation. In addition, with the transfer of vitamin E from feed to egg, oxidative stability was increased, shelf life was prolonged, the fatty acid composition in the egg yolk was improved (Mohiti-Asli et al., 2008) and the oxidation of omega-3 fatty acids was inhibited (Arab-Tehrany et al., 2012). Moreover, the lowest serum glucose, uric acid and creatinine concentrations, the highest HDL (high-density lipoprotein) concentration, low LDL (low-density lipoprotein) concentration, and low cholesterol and albumin concentrations were determined in quails fed with a diet containing $1000 \mathrm{mg} / \mathrm{kg}$ vitamin $\mathrm{E}$ and $\mathrm{C}$ for 42 days (Sigolo et al., 2018).

The purpose of the study was to investigate the effects of vitamin $\mathrm{E}$, thyme and rosemary extracts on production performance, egg quality and some blood parameters in laying hens.

\section{Material and Methods}

One hundred twelve 48-week-old Bovans genotype white laying hens between 48 and 56 weeks age were used in this research. In the study, second period cage laying hen feed was prepared according to the nutrient requirements reported by NRC (1994) (Table 1).

Table 1 Ingredients and chemical composition of the diet provided to the laying hens

\begin{tabular}{lllr}
\hline Ingredients & $\%$ & Chemical composition (analysed) & $\%$ \\
\hline Corn & 63 & Dry matter (\%) & 89.94 \\
Soybean meal & 16 & Crude protein (\%) & 16.32 \\
Sunflower meal & 4.5 & Ether extract (\%) & 3.72 \\
Limestone & 8.4 & Crude fibre (\%) & 3.25 \\
Full fat soybean & 2.8 & Ash (\%) & 11.13 \\
Meat bone meal & 2.5 & Calcium (\%) & 2.87 \\
Vitamin mineral premix ${ }^{1}$ & 2.5 & Total phosphorus (\%) & 0.48 \\
Vegetable oil & 0.1 & & $11.03 \mathrm{MJ} / \mathrm{kg}$ \\
L-Lysine & 0.09 & & \\
DL-Methionine & 0.04 & & \\
Methionine + Cysteine & 0.07 & & Metabolizable energy
\end{tabular}

\footnotetext{
${ }^{1}$ per kg. Vitamin A: 480.000 IU, Vitamin D3: 100.000 IU, Vitamin E: 1200 mg, Vitamin K3: 160 mg, Vitamin B1: 120 mg, Vitamin B2: 280 mg, Niacin: 1200 mg, Vitamin B6: 200 mg, Vitamin B12: 0.6 mg, Vitamin C: 2000 mg, Ca-DPantothenate: 400 mg, D-Biotin: 1.8 mg, Folic Acid: 40 mg, Choline chloride: 8000 mg, Zn: 240 mg, Cu: 40 mg, Mn: 180 mg, DL-Methionine: 47520 mg, P: 32400 mg, I: 40 mg, Se: 6 mg, NuPro: 200.000 mg, SPU 3 Phytase: 1800, Glucan: 3600 mg, Mannan: 2400 mg, HUT Protease: 75.000, CMCU Cellulase: 500, Canthaxanthin:140 mg.

${ }^{2}$ Calculated from values found in Larbier \& Leclercq (1994)
} 
The experimental diets and water were given ad libitum for eight weeks. One hundred and twelve laying hens were randomly divided into four groups, each comprising of four replicates of seven hens. Groups were determined as control, that is, an additive-free feed (basal diet), and one with vitamin E, one with rosemary extract and one with thyme extract added to the basal diet. The formation of the experimental groups, the active ingredients and the amounts of vitamin E, rosemary and thyme extracts that were added to the basal diet are given in Table 2. Some studies were used to select the levels of the feed additives, namely vitamin E (Wen et al., 2013; Çimrin \& Demirel 2016a; Abdallah et al., 2017; Niu et al., 2018), thyme (Radwan Nadia et al., 2008; Abd El-Hack \& Alagawany, 2015; Bulbul et al., 2018), and rosemary (Radwan Nadia et al., 2008; Alagawany \& Abd El-Hack, 2015; Belenli et al., 2015; Bulbul et al., 2018). Although the effect of a $200 \mathrm{mg} / \mathrm{kg}$ dose of vitamin $\mathrm{E}$ has been established, studies of appropriate doses for thyme and rosemary extract are still in progress. Therefore, average levels were taken. Rosemary and thyme extracts and vitamin E were supplied from a commercial company. A 16-hour lighting programme was provided using a fluorescent lamp in the henhouse in which the study was conducted.

Table 2 Experimental groups, the amount provided and chemical composition of the supplements provided to laying hens

\begin{tabular}{clrl}
\hline $\begin{array}{l}\text { Experimental } \\
\text { group }\end{array}$ & Additive & $\begin{array}{l}\text { Amount } \\
(\mathrm{mg} / \mathrm{kg})\end{array}$ & Active ingredients (\%) \\
\hline 1 & Control (additive-free) & & \\
\hline 2 & Vitamin E & 200 & DL- a-tocopherol acetate \\
\hline 3 & $\begin{array}{l}\text { Thyme (Thymbra spicata } \\
\text { L.) extract }\end{array}$ & 1000 & $\begin{array}{l}\text { Carvacrol (87.81), thymol (9.58), L-Linalool (0.86), borneol } \\
(0.74)\end{array}$ \\
\hline 4 & $\begin{array}{l}\text { Rosemary (Rosemarinus } \\
\text { officinalis L.) extract }\end{array}$ & 1000 & $\begin{array}{l}1.8 \text { cineole (34.08), camphor (27.95), alpha-Pinene (14.50), } \\
\text { borneol I(8.65), alpha-Terpineol (7.39), alpha-Thujone (1.09) } \\
\text { camphene (0.55) }\end{array}$ \\
\hline
\end{tabular}

${ }^{1}$ Active ingredients contained in the plant extracts and their amounts were provided by the manufacturer

The AOAC (2000) method was used to determine the nutrient composition in the diets of the laying hens. The samples were ashed in a muffle furnace before the calcium (Farese et al., 1967) and total phosphorus (ADAS, 1981) analyses were carried out. Crude fibre was determined (Crampton \& Maynard, 1938). The Larbier \& Leclercq (1994) equation was used to estimate the metabolizable energy levels in the samples.

Initial and final body weights of each hen were recorded before the experiment and at the end of the experiment, respectively. Mortality was recorded as it happened. The eggs were collected daily and egg production was given on a hen-day basis. The numbers of cracked eggs in each group were recorded daily (broken, cracked, no shell, etc.). Feed intake was recorded once every two weeks. The calculation was performed as grams of feed per day per hen. The unit of feed conversion ratio was calculated as grams of feed per gram of egg $(\mathrm{g} / \mathrm{g})$.

Twelve eggs were selected randomly from each group every 15 days. The quality criteria for eggs were determined by measuring and weighing 192 eggs in total. Each egg was weighed, and its index was determined with an instrument (B.V. Apparatenfabreik Van Doorn, No: 75 135/2, De Bilt, Holland). An egg breaking tester (static compression device, Dr-Ing. Georg Wazau Mess-+Prüftechnick, Berlin, Germany) was used to determine the eggshell breaking strength.

The eggs were broken on a glass-topped table. The measurement of eggshell thickness was performed on three parts (upper and lower ends and middle) using a micrometre (Mitutoya No. 2050-08, 0.01-20 mm; Kawasaki, Japan). A tripod micrometre (Mitutoyo, No. 2050S-19, 0.01-20 mm; Kawasaki, Japan) was used to measure the height of the albumen and the yolk. A digital calliper was used to measure albumen length and width, and yolk diameter. These values were used to calculate yolk index (yolk height $/$ yolk diameter) $x$ 100], albumen index [(albumen height / average of albumen length and albumen width) $x$ 100] and Haugh units $[100 \times \log (H+7.57-1.7 \mathrm{~W} 0.37)$, where $\mathrm{H}$ is albumen height and $\mathrm{W}$ is egg weight] (Card \& Nesheim 1972). Egg yolks were compared with the Roche colour fan to determine colour.

At the end of the experiment, blood samples of 16 hens that were selected randomly from each group (four from each replicate) were taken from the vena brachialis at the under-wing area. To analyse biochemical parameters, Architect c8000 system (Abbott Laboratories, USA) and the accompanying commercial kits were used, namely glucose (3L82-41 reagent kit), total cholesterol, (7D62 reagent kit) triglyceride (7D74 liquid kit), aspartate aminotransferase (AST) (7D81 kit), and alkaline phosphatase (ALP) 
(7D55-21).

Statistical analyses were done using SPSS 21.0 programme (SPSS Inc., Chicago, IL, USA, 2012). One-way ANOVA was performed to examine the differences among groups. Differences among the group means were tested with Duncan's test (Dawson \& Trapp, 2001).

\section{Results and Discussion}

Average levels of performance are given in Table 3. Supplementation of the diet with vitamin $E$, oregano extract or rosemary extract did not have any effect on live weight change, damaged egg ratio and feed conversion ratio $(P>0.05)$. Supplementation of vitamin $\mathrm{E}$ increased the egg production significantly compared with the groups that were supplemented with plant extracts $(P<0.001)$. In the experimental period, the control and vitamin E supplemented hens had the greatest rate of egg production. In contrast, Kaya \& Turgut (2012) reported that supplementation of $150 \mathrm{mg} / \mathrm{kg}$ vitamin E increased egg production. However, similar to the results found in this study, Mu et al. (2019) reported that supplementation of vitamin E did not affect egg production.

Table 3 Effects of dietary vitamin E, thyme and rosemary supplements on average productive performance traits of laying hens

\begin{tabular}{|c|c|c|c|c|c|c|}
\hline \multirow[b]{2}{*}{ Traits $^{1}$} & \multicolumn{4}{|c|}{ Treatment groups } & \multirow[b]{2}{*}{$\mathrm{F}$} & \multirow[b]{2}{*}{$P$-value } \\
\hline & Control & Vitamin E & Thyme & Rosemary & & \\
\hline IBW (g) & $1784.2 \pm 0.02$ & $1768.9 \pm 0.02$ & $1767.4 \pm 0.02$ & $1745.6 \pm 0.03$ & 0.48 & 0.695 \\
\hline FBW (g) & $1656.8 \pm 0.04$ & $1686.4 \pm 0.02$ & $1661.4 \pm 0.03$ & $1628.6 \pm 0.02$ & 0.72 & 0.544 \\
\hline AWC (g) & $127.43 \pm 31.39$ & $82.50 \pm 22.37$ & $106.00 \pm 19.54$ & $116.92 \pm 19.20$ & 0.66 & 0.557 \\
\hline EW (g) & $63.64^{a} \pm 0.20$ & $62.98^{\mathrm{b}} \pm 0.13$ & $64.62^{c} \pm 0.13$ & $62.89^{\mathrm{b}} \pm 1.14$ & 28.83 & $<0.001$ \\
\hline EP (\%) & $94.04^{a} \pm 0.58$ & $95.28^{a} \pm 0.51$ & $89.40^{b} \pm 0.65$ & $91.71^{c} \pm 0.65$ & 18.76 & $<0.001$ \\
\hline CE (\%) & $2.08 \pm 0.49$ & $1.31 \pm 0.60$ & $3.55 \pm 0.87$ & $2.93 \pm 0.96$ & 1.66 & 0.184 \\
\hline FCR $(g / g)$ & $1.83 \pm 0.03$ & $1.82 \pm 0.01$ & $1.87 \pm 0.02$ & $1.84 \pm 0.03$ & 0.72 & 0.546 \\
\hline $\mathrm{FI}$ (g/hen/d) & $109.29^{a} \pm 0.50$ & $109.33^{a} \pm 0.56$ & $110.37^{\mathrm{a}} \pm 0.54$ & $106.30^{b} \pm 0.58$ & 10.43 & $<0.001$ \\
\hline
\end{tabular}

${ }^{1}$ IBW: Initial body weight, FBW: Final body weight, AWC: Average weight change, EW: Egg weight, EP: Egg production, CE: Cracked eggs, FCR: Feed conversion ratio, FI: Feed intake

$a, b, c$ The difference between means with different superscript letters in the same row is significant $(P<0.05)$

Supplementation with thyme increased egg weight $(P<0.001)$, and reduced egg production significantly compared to the control, and vitamin $\mathrm{E}$ and rosemary supplemented groups $(P<0.001)$. Similarly, Abd El-Hack \& Alagawany (2015) also reported that supplementing laying hens with $6 \mathrm{~g} / \mathrm{kg}$ thyme powder increased egg weight and without changing the number of eggs produced. The decrease in the rate of egg production in the thyme supplemented group of the present study may have been a result of the increased egg weight. Others have also reported that thyme oil positively affected the egg production, egg weight and feed conversion ratio (Radwan Nadia et al., 2008; He et al., 2017). However, there are conflicting reports wherein thyme supplementation did not affect performance (Arpasova et al., 2015; Cufadar, 2018).

In the present study, supplemental rosemary significantly decreased egg weight, egg production and daily feed intake $(P<0.001)$ compared with the control group. This is thought to be associated with the decrease in the daily consumption of the rosemary supplemented diet which may be due to its pungent smell. There are contradictory reports in the literature about the effects of rosemary on poultry performance. Hajiazizi et al. (2016) and Torki et al. (2018) reported that the addition of rosemary to the diet did not affect the performance of laying hens. Similarly, Çimrin \& Demirel (2016a) reported that supplementing rosemary essential oil to the diet at $100 \mathrm{mg} / \mathrm{kg}, 200 \mathrm{mg} / \mathrm{kg}$, or $300 \mathrm{mg} / \mathrm{kg}$ did not affect the performance except for a reduction in feed intake. However, Alagawany \& Abd El-Hack (2015) indicated that the egg production and egg weight were increased by the addition of rosemary powder and that the diet was readily consumed. Similarly, Bolukbasi et al. (2008) also found that supplementation with $200 \mathrm{mg} / \mathrm{kg}$ rosemary essential oil increased the egg weight, reduced feed intake and increased the feed conversion ratio.

$\mathrm{He}$ et al. (2017) reported that $100 \mathrm{mg} / \mathrm{kg}$ oregano essential oil significantly increased egg weight. However, supplementation with either $50 \mathrm{mg} / \mathrm{kg}$ or $150 \mathrm{mg} / \mathrm{kg} \mathrm{mg} / \mathrm{kg}$ oregano essential oils resulted in hens producing eggs that were not different in weight from an unsupplemented control group. The hens studied by 
He et al. (2017), produced at daily rates of laying ranging from 92 to $97 \%$ which were similar to the rates of production observed in the control group and the vitamin $\mathrm{E}$ supplemented groups of the present study.

Average values for egg quality traits are given in Table 4. No differences were found in egg shape index, shell breaking strength, eggshell thickness, albumen index, yolk index, yolk colour, and Haugh unit average values $P>0.05)$. The supplementation with rosemary extract decreased the eggshell weight compared with the other experimental groups $(P<0.05)$.

Table 4 Effects of dietary vitamin E, thyme and rosemary supplements on egg quality criteria of laying hens

\begin{tabular}{lrrrrrr} 
& \multicolumn{5}{c}{ Treatment groups } \\
\cline { 2 - 5 } Traits & \multicolumn{1}{c}{ Control } & \multicolumn{1}{c}{ Vitamin E } & \multicolumn{1}{c}{ Thyme } & Rosemary & $F$ & $P$-value \\
\hline & $63.01 \pm 0.72$ & $62.12 \pm 0.60$ & $62.11 \pm 0.75$ & $61.56 \pm 0.63$ & 0.77 & 0.510 \\
Egg weight $(\mathrm{g})$ & $77.92 \pm 0.36$ & $74.86 \pm 1.91$ & $73.84 \pm 0.34$ & $76.88 \pm 0.41$ & 1.71 & 0.168 \\
Shape index $(\%)$ & $4.99 \pm 0.19$ & $4.90 \pm 0.15$ & $4.87 \pm 0.13$ & $4.54 \pm 0.14$ & 1.56 & 0.201 \\
Shell breaking strength $(\mathrm{kg} / \mathrm{cm} 2)$ & $376.11 \pm 0.39$ & $376.94 \pm 0.31$ & $376.86 \pm 0.56$ & $373.51 \pm 0.30$ & 0.16 & 0.926 \\
Shell thickness $(\mu \mathrm{m})$ & $7.00^{\mathrm{a}} \pm 0.09$ & $6.97^{\mathrm{a}} \pm 0.07$ & $7.07^{\mathrm{a}} \pm 0.11$ & $6.72^{\mathrm{b}} \pm 0.06$ & 3.05 & 0.031 \\
Shell weight $(\mathrm{g})$ & $7.72 \pm 0.15$ & $7.92 \pm 0.14$ & $7.79 \pm 0.16$ & $7.94 \pm 0.20$ & 0.39 & 0.758 \\
Albumen index $(\%)$ & $39.31 \pm 0.35$ & $39.73 \pm 0.28$ & $39.64 \pm 0.27$ & $3985 \pm 0.32$ & 0.57 & 0.635 \\
Yolk index $(\%)$ & $11.41 \pm 0.12$ & $11.47 \pm 0.11$ & $11.27 \pm 0.10$ & $11.44 \pm 0.15$ & 0.52 & 0.667 \\
Yolk color & $82.12 \pm 0.82$ & $82.05 \pm 0.62$ & $83.24 \pm 1.35$ & $82.55 \pm 0.96$ & 0.32 & 0.814 \\
Haugh unit & & & &
\end{tabular}

${ }^{a . b}$ The difference is significant among the averages with different letters in the same row $(P<0.05)$

Egg quality values were determined in 48 randomly selected eggs for each group. Therefore, it was thought that the decrease in weight of the eggshell might be attributed to the decrease that was found in egg weight (Table 4). The lack of differences in shell breaking strength and shell thickness supports this idea. These results are generally similar to those of other studies (Radwan Nadia et al., 2008; Hajiazizi et al., 2016; Çimrin \& Demirel, 2016a; He et al., 2017; Torki et al., 2018; Mohebbifar \& Torki, 2010; Cufadar, 2018). Contrary to the present results, Mansoub (2011) indicated that feeding of a thyme enriched supplement affected egg quality. In another study, Kaya \& Turgut (2012) found no significant difference between control, and sage, thyme, mentha and vitamin E supplemented groups in egg quality criteria. However, there were significant differences among those treatments in the shell breaking strength and shell weight which increased with the dosage level.

Average values of traits characterizing the blood lipid profile are given in Table 5. Supplementation of vitamin $\mathrm{E}$, thyme and rosemary to the diet did not affect blood AST and ALP levels $(P>0.05)$. The vitamin $E$ supplement also did not affect serum triglyceride and cholesterol levels. However, the supplementation of thyme and rosemary extracts decreased the triglyceride levels $(P<0.001)$. However, the cholesterol level was only decreased by the thyme supplement $(P<0.001)$.

Table 5 Effects of dietary vitamin E, thyme and rosemary supplements on the blood lipid profile of laying hens

\begin{tabular}{lrrrrrr}
\hline & \multicolumn{5}{c}{ Treatment groups } \\
\cline { 2 - 5 } Traits $^{1}$ & \multicolumn{1}{c}{ Control } & \multicolumn{1}{c}{ Vitamin E } & \multicolumn{1}{c}{ Thyme } & Rosemary & $\mathrm{F}$ & $P$-value \\
\hline Triglyceride $(\mathrm{mg} / \mathrm{dL})$ & $1288.3^{\mathrm{a}} \pm 44.98$ & $1229.7^{\mathrm{a}} \pm 34.14$ & $1088.5^{\mathrm{b}} \pm 27.53$ & $1119.5^{\mathrm{b}} \pm 23.77$ & 7.75 & $<0.001$ \\
Cholesterol $(\mathrm{mg} / \mathrm{dL})$ & $145.6^{\mathrm{a}} \pm 8.67$ & $131.2^{\mathrm{a}} \pm 9.99$ & $94.7^{\mathrm{b}} \pm 6.56$ & $129.8^{\mathrm{a}} \pm 9.23$ & 6.17 & $<0.001$ \\
AST $(\mathrm{u} / \mathrm{L})$ & $191.2 \pm 19.08$ & $163.0 \pm 7.25$ & $165 \pm 17.76$ & $205.6 \pm 17.26$ & 1.65 & 0.209 \\
ALP (u/L) & $577.8 \pm 66.87$ & $473.5 \pm 53.37$ & $508.0 \pm 40.81$ & $449.3 \pm 31.4$ & 1.25 & 0.309 \\
& & & & & & \\
\hline
\end{tabular}

\footnotetext{
${ }^{a . b}$ The difference is significant among the averages with different letters in the same row $(P<0.05)$

${ }^{1}$ AST: aspartate aminotransferase, ALP: alkaline phosphatase
} 
Abd El-Hack \& Alagawany (2015) also reported that supplementation of the diet for laying hens with 3 $\mathrm{g} / \mathrm{kg}$ and $6 \mathrm{~g} / \mathrm{kg}$ thyme reduced blood triglycerides and total cholesterol levels, and that LDL-cholesterol was reduced as the amount of thyme increased. Likewise, Rahimi et al. (2011) stated that blood triglyceride, total cholesterol, and LDL-cholesterol concentrations were significantly reduced when the diet of laying hens was supplemented with thyme. Hernandez et al. (2004) explained that the improvement the serum lipid profile resulted from thymol, which is found in high concentration in the thyme plant, improves lipid digestion by increasing lipase and bile production. Unlike the present results, Apaydin Yildirim et al. (2018) reported that the adding $100 \mathrm{mg} / \mathrm{kg}$ and $200 \mathrm{mg} / \mathrm{kg}$ rosemary to the diet of broilers reduced AST, increased the triglyceride, and did not affect the cholesterol level. Other studies have also reported that supplementation with rosemary powder or rosemary essential oil did not affect the serum lipid profile (Alagawany \& Abd ElHack, 2015; Çimrin \& Demirel, 2016b). Likewise, Ciftci et al. (2013) stated that the supplement of $250 \mathrm{mg} / \mathrm{kg}$ rosemary oil did not affect HDL-cholesterol, LDL-cholesterol, total cholesterol and triglyceride levels. Polat et al. (2011) reported that the rosemary supplements in broiler diets did not affect serum alanine aminotransferase and AST activities. However, they indicated that there was a difference in serum total cholesterol levels between rosemary leaves and rosemary essential oils, and rosemary leaves reduced the total cholesterol level. It should be noted that total phenol content are differs between rosemary essential oil, rosemary leaves and rosemary extract.

Olgun (2016) reported that some essential oils have improved the ovarian function, digestibility of nutrients and increased egg weight in poultry. The results that have been reviewed here involve use of different strains of the same plant, different methods being used to obtain the active compounds, and variation in the levels at which the supplements were provided. Additional differences among the previously described studies are not known precisely. However, an assessment of the combined results would contribute to knowledge of poultry nutrition. The quantity of medicinal and aromatic plants is important. It is crucial to harvest the plants in the appropriate season, to store them under healthy conditions, to process them with the correct methods, to mix them into the feed, and to store them under suitable conditions. In addition, it may be important to know the metabolisms of the powder, oil and extracts of the plants according to animal species, and to reveal these under the conditions in which they could be more effective in terms of future nutrition studies. Factors such as the amount that is added, regional differences, environmental effects, the harvest season and the type of plant processing can affect plant composition and levels of the bio-active compound.

\section{Conclusions}

Supplementation of laying hens with vitamin E, thyme or rosemary extracts has positive effects on performance and their blood lipid profile. The supplementation of vitamin $E$ improved egg performance. Thyme extract significantly increased the egg weight naturally. Because thyme and rosemary improved the serum lipid profile, and viewing the laying hen as a model system in which to study factors affecting human health, they may contribute to the reduction of cardiovascular diseases. Further and more detailed multidisciplinary studies on medical plants could be important for the poultry sector and human health.

\section{Acknowledgements}

The author would like to thank Etaş Afyon Poultry Company, Kırşehir, Turkey; Ege Lokman Plant Botanical Industry Trade Limited Company, Manisa, Turkey; and Vimar Food, Agriculture and Livestock Joint-Stock Company İstanbul, Turkey.

\section{Author Contributions}

TC was responsible for all facets of the research.

\section{Conflict of Interest Declaration}

The author declares that she has no affiliation with any organization or entity with any financial or non-financial interest that could bias the subject matter and outcomes that are discussed in this article.

\section{References}

Abdallah, Ehab A., Abd El-Samad, M.H., Abdel latif, A.M., Rezk, A.M. \& Yassein, Doaa M.M., 2017. Effect of dietary supplementation of grape seed extract or vitamin $\mathrm{E}$ as antioxidant on reproductive and physiological performance during summer season 2-aged male developed chickens. Egyptian Poultry Science 37, 137-153.

Abd El-Hack, M.A. \& Alagawany, M., 2015. Performance, egg quality, blood profile, immune function, and antioxidant enzyme activities in laying hens fed diets with thyme powder. J. Anim. and Feed Sci. 24, 127-133.

Abd El-Wareth, A.A.A., Kehrausa, S., Hippenstiela, F. \& Südekum, K. H., 2012. Effects of thyme and oregano on growth performance of broilers from 4 to 42 days of age and on microbial counts in crop, small intestine and caecum of 42-day-old broilers. Anim. Feed Sci. and Techn. 178, 198-202. 
ADAS, 1981. The analysis of agricultural materials. Ministry of Agriculture, Fisheries and Food, Agricultural Development and Advisory Service. 2nd edition. Her Majesty's Stationery Office, London, UK.

Alagawany, M. \& Abd El-Hack, M.A., 2015. The effect of rosemary herb as a dietary supplement on performance, egg quality, serum biochemical parameters, and oxidative status in laying hens. J. Anim. and Feed Sci. 24, 341-347.

AOAC (Association of Official Analytical Chemists), 2000. Official methods of analysis. 17th edition. AOAC International, Maryland, USA.

Apaydin Yildirim, B., Tunc, M., Gul, M., Yildirim, F. \& Yildiz, A., 2018. The effect of rosemary (Rosmarinus officinalis L.) extract supplemented into broiler diets on performance and blood parameters. GSC Biological and Pharmaceutical Science 2, 01-09.

Arab-Tehrany, E., Jacquot, M., Gaiani, C., Imran, M., Desobry, S. \& Linder, M., 2012. Beneficial effects and oxidative stability of omega-3 long-chain fatty acids. Trends in Food Science and Technology, 25, 24-33.

Arpasova, H., Galik, B., Hrncar, C., Fik, M., Herkel, R. \& Pistova V., 2015. The effect of essential oils on performance of laying hens. Anim. Sci. and Biotechn. 48, 8-14.

Attia, Y.A., Abd El-Hamid, E., El-Hamid, A., Abedalla, A.A., Berika, M.A., El-Gandy, M.F., Abou-Shehema, B.M., 2018. Effect of betaine, vitamin $C$, and vitamin $E$ on egg quality, hatchability, and markers of liver and renal functions in dual-purpose breeding hens exposed to chronic heat stress. European Poul. Sci. 82, DOI: 10.1399/eps.2018.226

Baser, K.H.C., 2008. Biological and pharmacological activities of carvacrol and carvacrol bearing essential oils. Current Pharmaceutical Design 14, 3106-3119.

Batista, N.R., Garcia, E.R.M., Oliveira, C.A.L., Arguelo, N.N. \& Souza, K.M.R., 2017. Trace mineral sources and rosemary oil in the diet of brown laying hens: Egg quality and lipid stability. Braz. J. Poult. Sci. 19, 663-672.

Behnamifar, A., Rahimi, S., Karimi Torshizi, M.A., Hasanpour, S. \& Mohammadzade, Z., 2015. Effect of thyme, garlic and caraway herbal extracts on blood parameters, productivity, egg quality, hatchability and intestinal bacterial population of laying Japanese quail. Iranian Journal of Veterinary Medicine (IJVM) 9, 179-187.

Belenli, D., Udum, D., Şule Cengiz, S. \& Polat U. 2015. Influence of various volatile oils as a dietary supplement on biochemical and performance parameters in broilers. Journal of Biology Environment Science 9, 47-55.

Beyazıtoglu S., 2009. The effects of supplemented dietary of alfa-tocopherol acetate, carvacrol, carnosic acid in laying hens on egg production, egg quality and immune system and under high temperature. Department of Animal Science Institute of Natural and Applied Sciences University of Cukurova, Adana, Turkey.

Botsoglou, N., Florou-Paneri, P., AOAC, E., Dotas, V., Giannenas, I., Koidis, A. \& Mitrakos, P., 2005. The effect of feeding rosemary, oregano, saffron and á-tocopheryl acetate on hen performance and oxidative stability of eggs. S. Afr. J. Anim. Sci. 35,143-151.

Bolukbasi, S.C., Erhan, M.K. \& Kaynar, O., 2008. The effect of feeding thyme, sage and rosemary oil on laying hen performance, cholesterol and some proteins ratio of egg yolk and Escherichia coli count in feces. Arch. Geflugelk. $72,231-237$.

Bulbul, T., Ozdemir, V., Ulutas, E. \& Bulbul, A. 2018. The effect of essential oils of myrtle, rosemary, and thyme on intestinal motility in broiler. Kocatepe Vet J.11, 394-401.

Card, L.E. \& Nesheim, M.C., 1972. Poultry production. 11th edition. Lea \& Febiger, Philadelphia, USA.

Christaki, E.V., Bonos, E.M. \& Florou-Paneri, P.C., 2011. Laboratory of nutrition comparative evaluation of dietary oregano, anise and olive leaves in laying Japanese quails. Braz. J. Poult. Sci. 13, 97-101.

Ciftci, M., Şimşek, U.G., Azman, M.A., Çerçi, I.H. \& Tonbak, F., 2013. The effects of dietary rosemary (Rosmarinus officinalis L.) oil supplementation on performance, carcass traits and some blood parameters of Japanese quail under heat stressed condition. J. Kafkas Univ. Fac. Vet. Med. 19, 595-599.

Çimrin, T. \& Demirel, M., 2016a. The effects of dietary rosemary (Rosmarinus officinalis L.) essential oil supplementation on laying hen performance, egg quality and oxidative stability of egg. Turkish J. Agr. Food Sci. and Techn. (TURJAF) 4, 113-119.

Çimrin, T. \& Demirel, M., 2016b. Influences of rosemary essential oil on some blood parameters and small intestine microflora laying hens. Turkish J. Agr. Food Sci. and Techn. (TURJAF) 4, 769-775.

Crampton, E.W. \& Maynard, L.A., 1938. The relation of cellulose and lignin content to nutritive value of animal feeds. J. The Journal of Nutr. 15, 383-395.

Cufadar, Y., 2018. Effects of dietary different levels of rosemary essential oil on performance and eggshell quality parameters in laying hens. Selcuk J Agr Food Sci. 32, 454-457.

Dawson, B. \& Trapp, R.G., 2001. Basic and clinical biostatistics. 3rd edition. Lange Medical Books/McGraw-Hill, New York, USA.

Estevez, M., Ramirez, R., Ventanas, S. \& Cava, R., 2007. Sage and rosemary essential oil versus BHT for the inhibition of lipid oxidative reactions in liver pate. LWT Food Sci. and Techn. 40, 58-65.

Farese, G., Schmidt, J.L. \& Mager, M., 1967. An automated method for the determination of serum calcium with glyoxal bis (2-hydroxyanil). Clinical Chemist 13, 515-520.

Gerzılov, V., Nikolov, A., Petrov, P., Bozakova, N., Penchev, G. \& Bochukov, A., 2015. Effect of a dietary herbal mixture supplement on the growth performance, egg production and health status in chickens. J. Central Eur. Agr. 16, 1027.

Hajiazizi, F., Torki, M. \& Habibian, M., 2016. Effects of rosemary essential oil and zinc on performance, egg quality traits, and some serum metabolites in laying hens. J. Livestock Sci. and Techn. 4, 01-06.

He, X., Hao, D., Liu, C., Zhang, X., Xu, D., Xu, X., Wang, J. \& Wu, R., 2017. Effect of supplemental oregano essential oils in diets on production performance and relatively intestinal parameters of laying hens. American J. Molec. Biology 7, 73-85. 
Hernandez, F., Madrid, J., Garcia, V., Orengo, J. \& Megias, M.D., 2004. Influence of two plant extracts on broiler performance, digestibility and digestive organ size, Poult. Sci. 4, 169-174.

Iqbal, R., Aziz, T., Sarfaraz, I., Shabir, R., Ansari, M.S, Malik, M.F., Saleem, R., Zahra, A. \& Mehwish, S., 2013. Effect of vitamin $E$ and selenium on immunity, egg production and liver function in laying hens (Hy-Line W-98). Middle East J. Sci. Res. 14, 1165-1170.

Kaya, A. \& Turgut, L., 2012. Effects of sage (Salvia officinalis), thyme (Thymbra spicata), mentha (Menthae piperitae) extracts and vitamin $\mathrm{E}$ supplementation at different levels into diets of hens on performance, egg quality and yolk TBARS values. J. Agr. Fac. Atatürk Univ. 43, 49-58.

Larbier, M. \& Leclercq, B., 1994. Nutrition and feeding of poultry. Nottingham University Press, Loughborough.

Mansoub, N.H., 2011. Assessment on effect of thyme on egg quality and blood parameters of laying hens. Annals of Biolog. Res. 2, 417-422.

Mohebbifar, A. \& Torki, M., 2010. Effects of adding mixed powder of garlic and thyme to diets included graded levels of rice bran on productive performance of laying hens and egg quality characteristics. Advances in Environmental Biology 4, 469-476.

Mohiti-Asli, M., Shariatmadari, F., Lotfollahian, H. \& Mazuji, M.T., 2008. Effects of supplementing layer hen diets with selenium and vitamin $\mathrm{E}$ on egg quality, lipid oxidation and fatty acids composition during storage. Canadian J. Anim. Sci. 88, 475-483.

Mu, Y., Zhang, K., Shiping Bai, S., Wang, J.P., Zeng, Q. \& Ding, X., 2019. Effects of vitamin E supplementation on performance, serum biochemical parameters and fatty acid composition of egg yolk in laying hens fed a diet containing ageing corn. J. Anim. Physiol. Anim. Nutr. 103,135-145

Niu, Z.Y., Min, Y.N. \& Liu, F.Z. 2018. Dietary vitamin E improves meat quality and antioxidant capacity in broilers by upregulating the expression of antioxidant enzyme genes. J. App. Anim. Research 46, 397-401.

NRC, 1994. Nutrient requirements of poultry. 9th edition. National Academy Press, Washington DC, USA.

Olgun, O., 2016. The effect of dietary essential oil mixture supplementation on performance, egg quality and bone characteristics in laying hens. Annals Anim. Sci. 16, 1115-1125.

Polat, U., Yesilbag, D. \& Eren, M., 2011. Serum biochemical profile of broiler chickens fed diets containing rosemary and rosemary volatile oil. J. Biolog. and Environmental Sci. 5, 23-30.

Radwan Nadia, L., Hassan, R.A., Qota, E.M. \& Fayek, H.M., 2008. Effect of natural antioxidant on oxidative stability of eggs and productive and reproductive performance of laying hens. Int. J. Poult. Sci. 7, 134-150.

Rahimi, S., Teymouri Zadeh, Z., Karimi Torshizi, M.A., Omidbaigi, R. \& Rokni, H., 2011. Effect of the three herbal extracts on growth performance, immune system, blood factors and intestinal selected bacterial population in broiler chickens. J. Agr. Sci. and Techn. 13, 527-539.

Sigolo, S., Khazaei, R., Seidavi, A., Ayasan, T., Gallo, A. \& Prandini, A., 2018. Effects of supra-nutritional levels of vitamin $\mathrm{E}$ and vitamin $\mathrm{C}$ on growth performance and blood parameters of Japanese quails. Italian J. Anim. Sci. 18, 140-146. https://DOI.org/10.1080/1828051X.2018.1500496

SPSS, 2012. IBM statistics for Windows, version 21.0. IBM Corp, Armonk, NY.

Torki, M., Sedgh-Gooya, S. \& Mohammadi, H., 2018. Effects of adding essential oils of rosemary, dill and chicory extract to diets on performance, egg quality and some blood parameters of laying hens subjected to heat stress. J. App. Anim. Res. 46, 1118-1126.

Ünlü, M., Vardar-Ünlü, G., Vural, N., Dönmez, E. \& Özbaş, Y.Z., 2009. Chemical composition, antibacterial and antifungal activity of the essential oil of Thymbra spicata L. from Turkey. Natural Product Res. 23, 572-579.

Wang, W., Wu, N., Zu, G. \& Fu, Y.J., 2008. Antioxidative activity of Rosmarinus officinalis L. essential oil compared to its main components. Food Chem. 108,1019-1022.

Wen, J., Zhang, L. \& Shan, A., 2013. The effect of vitamin E on laying performance and egg quality in laying hens fed corn dried distillers grains with solubles. Poultry Science 92, 2956-2964. 